\title{
Studies on $16 \alpha$-Hydroxylation of Steroid Molecules and Regioselective Binding Mode in Homology-Modeled Cytochrome P450-2C11
}

\author{
Hamed I. Ali, ${ }^{1}$ Morio Yamada, ${ }^{2}$ Yukihisa Fujita, ${ }^{3}$ Mitsuko Maeda, ${ }^{4}$ and Eiichi Akaho ${ }^{4}$ \\ ${ }^{1}$ Faculty of Pharmacy, Helwan University, Ain Helwan, Cairo 11795, Egypt \\ ${ }^{2}$ Department of Chemistry, Hyogo College of Medicine, 1-1, Mukogawa-cho, Nishinomiya, Hyogo 663-8501, Japan \\ ${ }^{3}$ Liberal Arts Center, Hyogo University of Health Sciences, 1-3-6, Minatojima, Chuo-ku, Kobe 650-8530, Japan \\ ${ }^{4}$ Faculty of Pharmaceutical Sciences, Center for Area Research and Development (CARD), Kobe Gakuin University, 1-1-3, Minatojima, \\ Chuo-ku, Kobe 650-8586, Japan \\ Correspondence should be addressed to Eiichi Akaho, akaho@pharm.kobegakuin.ac.jp
}

Received 8 December 2009; Revised 14 June 2010; Accepted 2 July 2010

Academic Editor: Edith Sim

Copyright (C) 2011 Hamed I. Ali et al. This is an open access article distributed under the Creative Commons Attribution License, which permits unrestricted use, distribution, and reproduction in any medium, provided the original work is properly cited.

\begin{abstract}
We investigated the $16 \alpha$-hydroxylation of steroid molecules and regioselective binding mode in homology-modeled cytochrome P450-2C11 to correlate the biological study with the computational molecular modeling. It revealed that there was a positive relationship between the observed inhibitory potencies and the binding free energies. Docking of steroid molecules into this homology-modeled CYP2C11 indicated that $16 \alpha$-hydroxylation is favored with steroidal molecules possessing the following components, (1) a bent A-B ring configuration (5 $\beta$-reduced), (2) C-3 $\alpha$-hydroxyl group, (3) C-17 $\beta$-acetyl group, and (4) methyl group at both the C-18 and C-19. These respective steroid components requirements were defined as the inhibitory contribution factor. Overall studies of the male rat CYP2C11 metabolism revealed that the above-mentioned steroid components requirements were essential to induce an effective inhibition of $\left[{ }^{3} \mathrm{H}\right]$ progesterone $16 \alpha$-hydroxylation. As far as docking of homology-modeled CYP2C11 against investigated steroids is concerned, they are docked at the active site superimposed with flurbiprofen. It was also found that the distance between heme iron and $\mathrm{C} 16 \alpha-\mathrm{H}$ was between 4 to $6 \AA$ and that the related angle was in the range of $180 \pm 45^{\circ}$.
\end{abstract}

\section{Introduction}

Cytochrome P450 (P450) constitutes a large superfamily of heme-containing enzymes capable of oxidizing a variety of substrates, both of endogenous (such as steroids) and exogenous (xenobiotics) origins [1-7]. Although a variety of P450s are able to metabolize a broad range of substrates, the enzymes often exhibit strict regio- and stereoselectivity towards pertinent compounds, such as various steroids [1]. One of the most active and versatile $\mathrm{P} 450$ is rat CYP2C11, a microsomal P450 isoform catalyzing more than $90 \%$ of steroid $16 \alpha$-hydroxylations [8-10]. It is well-known that several 3-keto-4-ene steroids such as progesterone and testosterone are metabolized in a gender-specific and predominant manner by the adult rat liver microsomes. In the male, these steroids are primarily metabolized into two oxidized (16 $\alpha$-hydroxyl and $6 \beta$-hydroxyl) products mainly by the respective, male-specific cytochrome $\mathrm{P} 450$ subforms, CYP2C11 and CYP3A2, while they are primarily metabolized into the $5 \alpha$-reduced products by female predominant $5 \alpha$ reductase [11]. Most of P450 structures reveal that the heme group is buried deep within the protein matrix, indicating that residues outside of the active site may also be required to guide the substrate into the heme pocket by recognizing substrates at the protein surface and/or comprising part of a substrate access channel [12].

In recent years, homology modeling has become an important tool to study the P450 function, especially in conjunction with experimental approaches [13]. A large amount of work has been directed to elucidating the substratebinding sites of various P450s, and the understanding of this field is now becoming increasingly important, mainly 
using the two powerful techniques, site-directed mutagenesis and computational molecular modeling of the relevant P450s [11, 12, 14-16]. In homology modeling, a 3-dimensional (3D) model of the protein is constructed based on its amino acid sequence and on the crystal structure of one or more reference proteins. This mainly involves a sequence alignment between the protein and the template(s) [17].

A challenge remains still for the development of a precise 3D-crystal structure of CYP2C11. Therefore, in this study, an investigation was carried out on the docking mode of 71 different steroid molecules against a computationally homology-modeled 3D-structure of CYP2C11, so as to see a correlation of the biologically obtained results with the AutoDock computational results.

\section{Results and Discussion}

2.1. Homology Modeling of CYP2C11. Homology modeling of CYP2C11 was performed by the use of SwissModel software [13, 18]. The amino acid sequence of CYP2C11 structure was used as target protein. Various proteins of 500 residues were used as templates, including P450 2C9 with warfarin bound, PDB code, log5 [19]; P450 2C9, PDB code, $\log 2$ [19]; P450 2C9 complexed with flurbiprofen bound, PDB code, 1r9o [20]; P450 2C8, PDB code, 1pq2 [21]; P450 2C5/3LVdH complexed with a bound substrate, 4-methyl-N-methyl-N-(2-phenyl-2Hpyrazol-3-yl)benzenesulfonamide (DMZ), PDB code, 1n6b [13]; P450 2C5/3LVdH complexed with diclofenac, PDB code, 1nr6 [14]; P450 2C5, PDB code, ldt6 [15]; P450 2B4 with 4-(4-Chlorophenyl) imidazole bound, PDB code, 1suo [22]; P450 2B4, PDB code, 1 po5 [22]; P450 2A6 with methoxsalen bound, PDB code, 1zll [23]; P450 2A6 with coumarin bound, PDB code, 1z10 [17]; P450 3A4, PDB code, 1tqn [24]; P450 3A4 with metyrapone bound, PDB code, 1w0g [25]; P450 3A4, with PDB code, 1w0e [25]; P450 $3 \mathrm{~A} 4$ with progesterone bound, PDB code, 1w0f [20]; CYP51 with estriol bound, PDB code, $1 \mathrm{x} 8 \mathrm{v}$ [26]; CYP51 in ferric low spin state, PDB code, 1h5z [20]; C37L/C151T/C442Atriplet mutant of CYP51, PDB code, lu13 [27]; CYP51 with 4-phenylimidazole bound, PDB code, 1e9x [27]; CYP51 with fluconazole bound, PDB code, 1eal [27].

Mammalian CYP450 proteins recognize and metabolize diverse xenobiotics such as drug molecules, environmental compounds, and pollutants. Human CYP450 proteins, CYP1A2, CYP2C9, CYP2C19, CYP2D6, and CYP3A3 are the major drug-metabolizing isoforms, and contribute to the oxidative metabolism of more than $90 \%$ of the drugs in current clinical use [20]. Therefore, the organism for which any of our P450 structures/models study originate from are mostly human [13-15, 18-27].

The pairwise sequence alignments of the target sequence with that of template was carried out and the sequence identity of templates with the target sequence is shown in Table 1. The amino acid sequence of the aligned protein templates of chain A of P450 2C9-flurbiprofen (1r9o), P450 2C9-warfarin ( $\log 5)$, and P450 2C9 $(\log 2)$ exhibited the highest percentage of identity with that of CYP2C11 in the range of $83.5 \%, 75.9 \%$, and $75.9 \%$, respectively. The chain A of the templates of CYP51-estriol (1x8vA), CYP51 (1h5zA), C37L/C151T/C442A (1u13A), CYP51-4phenylimidazole (1e9xA), and CYP51-fluconazole (1ea1A), whose percentages of identity were $23.3 \%, 23.9 \%, 23.9 \%$, $23.9 \%$, and $23.9 \%$, respectively, had been rejected due to their too low similarities with the target sequence.

\subsection{Docking of Representative Steroids in the Embedded Flur-} biprofen Pocket. Seventy one different steroid molecules (171 ) (Table 2 ) were docked in the $16 \alpha$-hydroxylation orientation into the biding site of the homology-modeled CYP2C11, where the ligand, flurbiprofen (FLP), was embedded. Affinity orientation between the protein and the substrate are predominately hydrophobic. The side chains of Asn107, Ile113, Phe114, Asn204, Phe205, Phe208, Phe237, Thr292, Asp293, Gly296, Ala297, Glu300, Thr301, and Leu366 lay within $4 \AA$ of all docked steroid molecules as pointed out in Figure 2, where Gly296, Ala297, and Leu366 are hidden for clarity. Seven of these amino acids, namely Phe114, Asn204, Asp293, Gly296, Ala 297, Thr301, and Leu366 corresponded identically to the key amino acid residues identified in the earlier studies of the binding site of flurbiprofen in CYP2C9 (PDB code, 1r9o) [20], as cited in PDP sum, http://www.ebi.ac.uk/pdbsum/, accessed on November 12, 2008.

The amino acid sequence of the aligned protein templates of chain A of 1r9o.pdb, $\log 5$. pdb, and $\log 2 . p d b$ exhibited the highest percentage of identity with that of CYP2C11 in the range of $83.5 \%, 75.9 \%$, and $75.9 \%$, respectively, as shown in Figure 1 and Table 1. The above two findings strongly support the hypothesis that the key amino acid residues of CYP2C11 are identical, for the most part, to that of CYP2C9. However, this finding must be further verified experimentally. Figure 2 illustrates the ribbon schematic presentations of the homology model of CYP2C11 in sequence alignment with the warfarin-bound CYP2C9 (PDB code, $\log 5$ ) [19], with CYP2C9 (PDB code, $\log 2$ ) [19], and with the flurbiprofen-bound CYP2C9 (PDB code, 1r9o). The details of these sequence views are shown in Figure 1, including both the proposed key amino acid residues and the different and similar residues of the aligned protein sequences.

\subsection{Hydroxylation of Steroids and Their Docking Conforma-} tion within the Active Site. The ideal conformation of the steroid molecules within their binding site in varieties of P450s was proposed by many investigator [28-33]. They reported that the respective substrates for prokaryotic $\mathrm{P} 450 \mathrm{~s}$ cam, and eryF are positioned in such a way that a substrate is hydroxylated at a distance of 4.5 and $4.8 \AA$ from the heme Fe to the hydroxylated atom [34]. These substrates were also oriented in such a way that the hydrogen, which is abstracted during the reaction, be located within $2 \AA$ of the oxygen of the oxy-preferryl intermediate [13]. It is also reported that the docked substrates should be located with the distance between their oxidation site $(\mathrm{C} 16)$ and the heme iron being $6 \AA$ and with the $\mathrm{C}-\mathrm{H}-\mathrm{Fe}$ angle at $\mathrm{C} 16$ being $180^{\circ}$ [28]. The $\mathrm{C}-\mathrm{H}$ bond in $\mathrm{C}-\mathrm{H}-\mathrm{Fe}$ sequence should be 


\begin{tabular}{|c|c|c|c|c|c|c|c|}
\hline SEQALI & P08683 & 30 & $\mathbf{P}$ & PGPTPLP I IG & NTLQ I Y MKD I & GQS I KKF S K V & YGP I F T L Y $\underline{\mathrm{L}} \mathrm{G}$ \\
\hline SEQALI & $\log 5 \mathrm{~A}$ & 30 & $\mathrm{P}$ & PGPT P LPV IG & N I LQ I G I KD I & 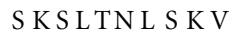 & YGP V F T L Y F G \\
\hline SEQALI & $\log 2 \mathrm{~A}$ & 30 & $\mathrm{P}$ & PGPT P LPV IG & N I LQ I G I KD I & S KS L TNL S K V & YGP VF T L Y F G \\
\hline SEQALI & $1 \mathrm{r} 9 \mathrm{oA}$ & 26 & R GK L P & PGPTP - . - L & PLQ I - G I KD I & S K S LTN L S K V & YGP VF T L Y F G \\
\hline SEQALI & P08683 & 71 & 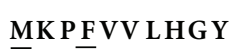 & EAVKEAL VDDL & GEE F S G RG $\underline{S}$ F & $\mathrm{P} V \underline{\mathrm{S}} \mathrm{ER} \underline{\mathrm{VN}} \underline{\mathrm{K}} \mathrm{G} \underline{\mathrm{L}}$ & - - G $\underline{\mathrm{V}} \underline{\mathrm{I} F \mathrm{~F}} \mathrm{~N} \underline{\mathrm{M}}$ \\
\hline SEQALI & $\log 5 \mathrm{~A}$ & 71 & $\bar{L}$ K P I VV LHGY & EAVKEAL I DL & GEE F S GRG I F & P LAERANRG F & - G G VF S NGK \\
\hline SEQALI & $\log 2 \mathrm{~A}$ & 71 & L K P I VV LHGY & EAVKEAL I DL & GEE F S G RG I F & P LAERANRGF & - - G I VF S NGK \\
\hline SEQALI & $1 \mathrm{r} 9 \mathrm{oA}$ & 71 & L K P I VV LHGY & EAVKEAL I DL & GEE F S GRG I F & P LA - - ERANR & GFG I VF S NGK \\
\hline SEQALI & P08683 & 119 & 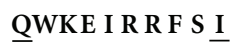 & MT L RT FGMGK & RT I EDR I QE E & AQCLVEE L R K & $\underline{S}$ KG A P F D P T F \\
\hline SEQALI & $\log 5 \mathrm{~A}$ & 119 & $\bar{K} W K E$ I R R F S L & MT L RNFGMGK & R S I EDR VQE E & A R CLVE E L R K & $\overline{\mathrm{T}} \mathrm{KAS}$ P $\bar{C} \mathrm{D}$ P T F \\
\hline SEQALI & $\log 2 \mathrm{~A}$ & 119 & KWKE I R R F S L & MT L RNFGMGK & RS I EDR VQE E & A RCLVEE L R K & TKA S P CD P T F \\
\hline SEQALI & $1 \mathrm{r} 9 \mathrm{oA}$ & 119 & KWKE I R R F S L & MT L RNFGMGK & RS I EDR VQE E & A RCLVEE L R K & TKA S P CD P T F \\
\hline SEQALI & P08683 & 169 & I L GCAP CNV I & CS I I F QNR FD & YKD $\underline{P}$ T F LNLM & HRFNENFR L F & S S PWLLQV $\underline{\text { C N } \underline{T}}$ \\
\hline SEQALI & $\log 5 \mathrm{~A}$ & 169 & I L GCAP CNV I & CS I I FHKR FD & Y KDQQF LN LM & E KLNEN I E I L & S S PW I QV Y N N \\
\hline SEQALI & $\log 2 \mathrm{~A}$ & 169 & I L GCAP CNV I & CS I I FHKR FD & Y KDQQF LN LM & E KLNEN I E I L & S S PW I QV Y NN \\
\hline SEQALI & $1 \mathrm{r} 9 \mathrm{oA}$ & 169 & I L GCAP CNV I & CS I I FHKR FD & YKDQQF LNLM & E KLNEN I K I L & S S PWI P I I - - \\
\hline SEQALI & P08683 & 219 & F P A I I DYF PG & SHNQVLKN FF & $\underline{\mathrm{Y}} \mathbf{\mathrm { KN }} \underline{\mathrm{V}} \mathrm{L}$ L E KV & KEHQE S L D KD & NPㅁF I D C F L \\
\hline SEQALI & $\log 5 \mathrm{~A}$ & 219 & F P A $\overline{L L D Y F P G}$ & THNKL LKNVA & FMK S Y I LE KV & K EHQE S MDMN & NPQDF I D C F L \\
\hline SEQALI & $\log 2 \mathrm{~A}$ & 219 & F P AL LDY F P G & THNK L LKNVA & FMK S Y I LE KV & KEHQE S MDMN & NPQDF I D C F L \\
\hline SEQALI & $1 \mathrm{r} 9 \mathrm{oA}$ & 242 & $\ldots-$ - DYF PG & THNK L LKNVA & FMK S Y I LEKV & K EHQE SMDMN & NPQDF I D C F L \\
\hline SEQALI & P08683 & 269 & 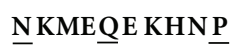 & $\underline{\text { QS EFT TLES LV }}$ & ATVTDMFGG & T ETTT S T T L R Y & $\underline{G} L L L L L K H \underline{D}$ \\
\hline SEQALI & $\log 5 \mathrm{~A}$ & 269 & MKME KE KHNQ & PSEFT IES LE & NTAVDL FGAG & TETTST T L R Y & A L L L L L K H P E \\
\hline SEQALI & $\log 2 \mathrm{~A}$ & 269 & MKME KE KHNQ & PSEFT IES LE & NTAVDL FGAG & T ETTS T T L R Y & A L L L L L K H P E \\
\hline SEQALI & $1 \mathrm{r} 9 \mathrm{oA}$ & 269 & MKME KE KHNQ & PSEFT IES LE & NTAVDL FGAG & TETTS T T L R Y & A L L L L L K H P E \\
\hline SEQALI & P08683 & 319 & VT AKVQEE I E & RV I GRNR S PC & MKDR S QMP Y T & DAVVHE I QR Y & I D L V P T NLP H \\
\hline SEQALI & $\log 5 \mathrm{~A}$ & 319 & V T AKVQEE I E & RV I GRNR S PC & MQDR S HMP Y T & DAVVHE VQR Y & I DL L P T S L P H \\
\hline SEQALI & $\log 2 \mathrm{~A}$ & 319 & VT AKVQEE I E & RV I GRNR S PC & MQDR S HMP Y T & DAVVHE VQR Y & I D L L P T S L P H \\
\hline SEQALI & $1 \mathrm{r} 9 \mathrm{oA}$ & 319 & VT AKVQEE I E & RV I GRNR S PC & MQDR S HMP Y T & DAVVHE V QR Y & I D L L P T S L P H \\
\hline SEQALI & P08683 & 369 & 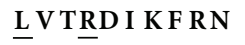 & Y F I P KGT NVI & 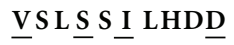 & KEFPNP E $\underline{\text { K F D }}$ & P $\underline{G} H$ F L D E $\underline{R} G N$ \\
\hline SEQALI & $\log 5 \mathrm{~A}$ & 369 & $\overline{\mathrm{A}} \mathrm{V}$ TC $\mathrm{C}$ I K F RN & Y $\bar{L}$ I P KGT T IL & 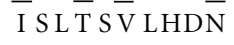 & K E F PNP EM F D & $P \bar{H} H$ F L D E $\bar{G}$ G N \\
\hline SEQALI & $\log 2 \mathrm{~A}$ & 369 & A V TCD I K F RN & YL I P KGT T I L & I S L T S V LHDN & KE F PNP EMF D & PHH F L D G GN \\
\hline SEQALI & $1 \mathrm{r} 9 \mathrm{oA}$ & 369 & A V TCD I K F RN & YL I P KGT T I L & I S L T S V LHDN & KE F PNP EMF D & PHH F LD E GGN \\
\hline SEQALI & P08683 & 419 & F KKS DY FMP F & S AGKR I C & ALA $\underline{\text { RTE LF L F }}$ & 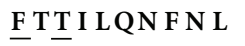 & K S L VD纨 $\underline{\mathrm{D} I} \mathrm{D}$ \\
\hline SEQALI & $\log 5 \mathrm{~A}$ & 419 & F K K S K Y FMP F & S AGKR I CV GE & A L A $\overline{G M} E$ L F L F & L T S I LQN F N L & K S L VDP K N L D \\
\hline SEQALI & $\log 2 \mathrm{~A}$ & 419 & F K KS KY FMP F & S AGKR I CV GE & A LAGME L F L F & L T S I LQN F N L & K S L VDP K N L D \\
\hline SEQALI & $1 \mathrm{r} 9 \mathrm{oA}$ & 419 & F K KS KY FMP F & S AGKR I CV GE & A LAGME L F L F & L T S I LQN F N L & K S L VDP K N L D \\
\hline SEQALI & P08683 & 469 & T T PA I S GF FH & L P P F Y EAC F I & PV - & & \\
\hline SEQALI & $\log 5 \mathrm{~A}$ & 469 & T T PVVNG $\overline{F A S}$ & $\overline{\mathrm{V}} \mathrm{P} P$ F Y $\overline{Q L} \mathrm{C} F \mathrm{I}$ & PV - - & & \\
\hline SEQALI & $\log 2 \mathrm{~A}$ & 469 & T T PVVNGFAS & VP P F YQL C F I & PV - - & & \\
\hline SEQALI & $1 \mathrm{r} 9 \mathrm{oA}$ & 469 & T T PVVNGFAS & VP P F YQL C F I & P IHH & & \\
\hline
\end{tabular}

Figure 1: The sequence alignment among CYP2C11(Swiss-prot entry code: P08683), and chain A of warfarin-bound CYP2C9 (PDB code: $\log 5$ ), CYP2C9 (PDB code: $\log 2$ ), flurbiprofen-bound CYP2C9 (PDB code:1r9o). The first 29, 29, 29, and 25 amino acids of these proteins, respectively, are not shown and were not modeled. Residues of target CYP2C11 are highlighted in bold letters, the amino acids of the binding site are indicated by boxed text, the nonmatched amino acids are underlined, the identical key amino acid residues of 1rgo with that of CYP2C11 are shown in bold Arial black letters, and the amino acid sequences of chain B of $\log 5$ and $\log 2$ were deleted due to their identical amino acid composition to their chain A. 
TABle 1: Percentage of sequence identity of the pairwise alignment of various template sequences with the target protein sequence (CYP2C11).

\begin{tabular}{|c|c|c|c|c|c|}
\hline Crystal structures & $\begin{array}{l}\text { PDB code } \\
\text { and chain }{ }^{\mathrm{c}}\end{array}$ & $\begin{array}{c}\% \\
\text { identity }\end{array}$ & Crystal structures & PDB code & $\%$ identity \\
\hline CYP2C9-flurbiprofen & 1r9oA & 83.46 & CYP2A6-methoxsalen & $1 z 11 D$ & 52.7 \\
\hline CYP2C9-warfarin & $\log 5 \mathrm{~A}$ & 75.9 & CYP2A6-coumarin & $1 z 10 \mathrm{~A}$ & 52.6 \\
\hline CYP2C9 & $\log 2 \mathrm{~A}$ & 75.9 & CYP2A6-coumarin & $1 z 10 B$ & 52.3 \\
\hline CYP2C9-warfarin & $\log 5 \mathrm{~B}$ & 75.9 & CYP2A6-coumarin & $1 \mathrm{z} 10 \mathrm{C}$ & 52.7 \\
\hline CYP2C9 & $\log 2 B$ & 75.9 & CYP2A6-coumarin & $1 z 10 \mathrm{D}$ & 52.7 \\
\hline СYP2C8 & $1 \mathrm{pq} 2 \mathrm{~A}$ & 74.3 & CYP3A4 & $1 \operatorname{tqn} A$ & 28.02 \\
\hline СYP2C8 & $1 \mathrm{pq} 2 \mathrm{~B}$ & 74.3 & CYP3A4-progesterone & 1w0fA & 30.05 \\
\hline CYP2C5/3LVdH-DMZ & $\ln 6 b$ & 73.95 & CYP3A4-metyrapone & 1w0gA & 34.25 \\
\hline CYP2C5/3LVdH-diclofenac & lnr6A & 73.95 & CYP3A4 & $1 \mathrm{w} 0 \mathrm{eA}$ & 28.2 \\
\hline CYP2C5 & $1 \mathrm{dt} 6 \mathrm{~A}$ & 71.96 & CYP51-Estriol & $1 \mathrm{x} 8 \mathrm{vA}$ & 23.33 \\
\hline CYP2B4-CPZ & 1 suoA & 55.1 & CYP51 & $1 \mathrm{~h} 5 \mathrm{zA}$ & 23.9 \\
\hline CYP2B4 & 1 po5A & 54.9 & C37L/C151T/C442A-triplet mutant of CYP51 & $1 \mathrm{u} 13 \mathrm{~A}$ & 23.9 \\
\hline CYP2A6-methoxsalen & $1 \mathrm{z} 11 \mathrm{~A}$ & 52.2 & CYP51-4-phenylimidazole & $1 \mathrm{e} 9 \mathrm{xA}$ & 23.9 \\
\hline CYP2A6-methoxsalen & $1 \mathrm{z} 11 \mathrm{~B}$ & 52.6 & CYP51-fluconazole & $1 \mathrm{ea} 1 \mathrm{~A}$ & 23.9 \\
\hline CYP2A6-methoxsalen & $1 \mathrm{z} 11 \mathrm{C}$ & 52.7 & & & \\
\hline
\end{tabular}

${ }^{a}$ DMZ: 4-Methyl- $N$-methyl- $N$-(2-phenyl-2H-pyrazol-3-yl)benzenesulfonamide.

${ }^{\mathrm{b}} \mathrm{CPZ}$ : 4-(4-Chlorophenyl)-imidazole.

${ }^{c}$ The first four symbols represent PDB code and the last symbol, A, B, C, or D, represents the amino acid chain involved in sequence alignments.

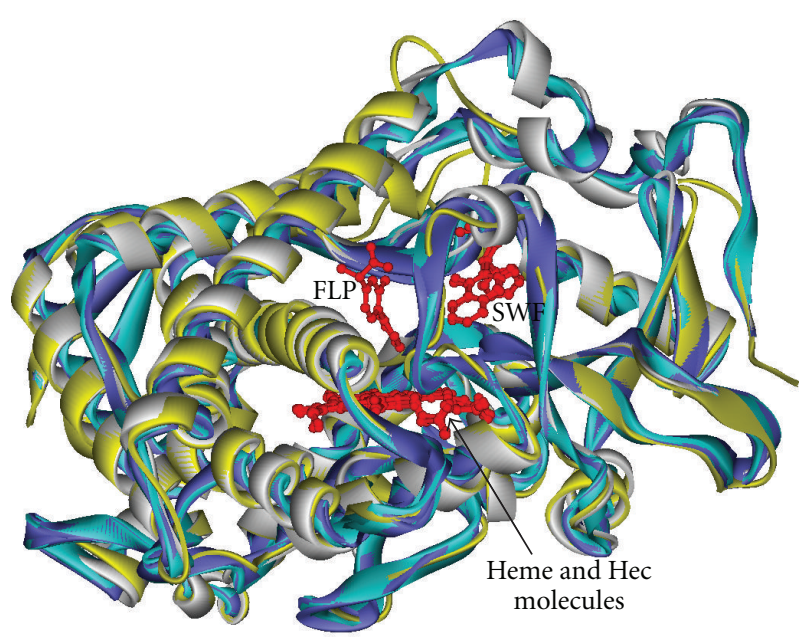

Figure 2: The Homology-modeled structure of CYP2C11, in white solid ribon in sequence alignment with the solid ribon crystal structures of CYP2C9 ( $\log 5)$ in cyan with its bound ligandSWF(swarfarin), CYP2C9 ( $\log 2)$ in violet, and CYP2C9 (1r9o) in yellow with its bound ligand, FLP (Flurbiprofen). Molecules of heme and $\mathrm{Hec}$ of the aligned proteins in red ball and stick are shown in exact superposition within the binding site.

perpendicular to the heme surface. The substrate was usually placed at a position equivalent to that of camphor in the P450cam crystallographic structure, which gives a distance of about 4.2-4.9 $\AA$ between the oxidation sites and the heme iron. However, molecular dynamics simulations of camphorbound P450cam suggests that the average distance between the carbon atom, at which hydroxylation takes place, and the heme iron is $5.3 \AA$.
Szklarz et al. [8] proposed that for catalysis to occur the following conditions must be met: (1) the distance between the hem iron and the carbon, at which the hydroxylation takes place, must be $5.6-6 \AA$ to allow room for the active oxygen, which results in the carbon to active oxygen distance of 3.9-4.2 $\AA$, and the hydrogen to oxygen distance of 2.3$3.1 \AA$ and (2) the angle between the carbon, the hydrogen, and the heme iron (or active oxygen) should be close to $180^{\circ}\left(180 \pm 45^{\circ}\right)$ to promote hydrogen bond formation. Therefore, the analysis of our docking study revealed that the results met the above-mentioned requirements for catalysis, (1) and (2) proposed by Szklarz et al. [8]. That is, the binding orientation would place a potential site for C-16 $\alpha$ hydroxylation within 5-6 $\AA$ of the heme iron and the angle between the carbon, the hydrogen and the heme iron (or active oxygen) should be as close as possible to $180^{\circ}$ (180 \pm $45^{\circ}$ ).

Analysis of the docking results revealed that there were a considerable number of conformations flexibilities of the docked substrates oriented in order to meet the above-mentioned conditions, and it was noticed that many conformations were docked within the required distance (4$6 \AA)$, but not by the required angle $\left(180 \pm 45^{\circ}\right)$.

2.4. The Docking Energy of Binding and the Experimentally Observed Inhibitory Potency. Inhibitor docking studies revealed that there was a reasonable positive relationship between their observed inhibitory potencies against $[3 \mathrm{H}] \mathrm{PROG} 16 \alpha$-hydroxylation and the number of conformations met with the above mentioned condition (Table 2). In this type of a comparative study between biological potency and computational simulation, it is of our primary concern 
TABLE 2: The inhibitory potency of various steroids on [3H] PROG $16 \alpha$-hydroxylating activity by male rat liver microsomes and their AutoDock results including the binding free energy, the inhibition constant, the distance between C16 carbon atom and feme iron and the angle between $\mathrm{C} 16$ carbon atom, C16 $\alpha$-hydrogen, and heme Fe iron.

\begin{tabular}{|c|c|c|c|c|c|c|}
\hline No. & Trivial name $\left({ }^{\circ}\right)$ & $\begin{array}{l}{\left[{ }^{3} \mathrm{H}\right] \text { PROG } 16 \alpha-} \\
\text { hydroxylation } \\
\left(\mathrm{IC}_{40} \times 10^{-7} \mathrm{M}\right)^{\mathrm{a}}\end{array}$ & $\begin{array}{l}\Delta G_{b} \\
(\mathrm{kcal} / \mathrm{mol})\end{array}$ & $\begin{array}{l}\text { Inhibition } \\
\text { constant } \\
\left(K i, \times 10^{-8}\right)\end{array}$ & $\begin{array}{l}\text { Distance } \\
(\AA)\end{array}$ & $\begin{array}{l}\text { Angle } \\
(0)\end{array}$ \\
\hline \multicolumn{7}{|c|}{ (A) 4-Pregnene steroids } \\
\hline (1) & Progesterone & 7.55 & -10.93 & 0.976 & 5.73 & 144.8 \\
\hline (2) & $3 \beta$-Hydroxyprogesterone & 2.55 & — $^{\mathrm{b}}$ & - & - & - \\
\hline (3) & $6 \beta$-Hydroxyprogesterone & $>10 \mu \mathrm{M}^{\mathrm{c}}$ & - & - & - & - \\
\hline (4) & $6 \beta$-Acetoxyprogesterone & 7.40 & - & - & - & - \\
\hline (5) & $11 \alpha$-Hydroxyprogesterone & $>10 \mu \mathrm{M}$ & - & - & - & - \\
\hline (6) & $11 \alpha$-Acetoxyprogesterone & $>10 \mu \mathrm{M}$ & - & - & - & - \\
\hline (7) & $11 \beta$-Hydroxyprogesterone & $>10 \mu \mathrm{M}$ & -11.32 & 0.504 & 5.90 & 139.3 \\
\hline (8) & $16 \alpha$-Hydroxyprogesterone & $>10 \mu \mathrm{M}$ & - & - & - & - \\
\hline (9) & 16 $\alpha$-Methylprogesterone & $>10 \mu \mathrm{M}^{d}$ & -9.97 & 4.88 & 5.32 & 159.1 \\
\hline (10) & 18-Hydroxyprogesterone & $>10 \mu \mathrm{M}$ & - & - & - & - \\
\hline (11) & 19-Hydroxyprogesterone & $>10 \mu \mathrm{M}$ & - & - & - & - \\
\hline (12) & 19-Norprogesterone & $>10 \mu \mathrm{M}$ & - & - & - & - \\
\hline (13) & $20 \alpha$-Hydroxyprogesterone & $>10 \mu \mathrm{M}$ & - & - & - & - \\
\hline (14) & 21-Hydroxyprogesterone & $>10 \mu \mathrm{M}$ & -10.56 & 1.83 & 4.73 & 139.7 \\
\hline (15) & 21-Acetoxyprogesterone & $>10 \mu \mathrm{M}$ & - & - & - & - \\
\hline$(16)$ & Corticosterone & $>10 \mu \mathrm{M}$ & -10.54 & 1.87 & 4.75 & 143.6 \\
\hline \multicolumn{7}{|c|}{ (B) 5-Pregnene steroids and cholesterol } \\
\hline (17) & Pregnenolone & 1.42 & -11.29 & 0.532 & 5.76 & 139.2 \\
\hline (18) & Pregnenolone-3-acetate & 8.00 & -9.52 & 10.6 & 4.92 & 166.8 \\
\hline (19) & Pregnenolone-3-sulfate & 1.95 & - & - & - & - \\
\hline$(20)$ & 5-Pregnene-3,20-dione & $>10 \mu \mathrm{M}$ & - & - & - & - \\
\hline (21) & $20 \alpha$-Hydroxypregnenolone & $>10 \mu \mathrm{M}$ & -10.61 & 1.67 & 5.90 & 134.8 \\
\hline$(22)$ & 21-Hydroxypregnenolone & 4.62 & -10.86 & 1.09 & 5.95 & 144.8 \\
\hline (23) & 21-Acetoxypregnenolone & 6.00 & -12.20 & 0.114 & 4.98 & 136.3 \\
\hline (24) & 21-Sulfatepregnenolone & $>10 \mu \mathrm{M}$ & -9.69 & 7.89 & 4.53 & 139.7 \\
\hline$(25)$ & 5-Pregnen-3 $\beta$-ol & $>10 \mu \mathrm{M}$ & - & - & - & - \\
\hline$(26)$ & Cholesterol & $>10 \mu \mathrm{M}$ & -9.79 & 6.65 & 6.0 & 159.2 \\
\hline \multicolumn{7}{|c|}{ (C) $5 \alpha$-or $5 \beta$-Pregnane steroids } \\
\hline (27) & $5 \alpha$-Pregnan-3,20-dione & 7.20 & -9.51 & 10.6 & 5.86 & 149.1 \\
\hline$(28)$ & $5 \beta$-Pregnan-3,20-dione & 3.95 & -10.45 & 2.20 & 4.93 & 135.0 \\
\hline (29) & $3 \alpha$-Hydroxy-5 $\alpha$-pregnan-20-one & 0.62 & -10.90 & 1.03 & 5.82 & 148.9 \\
\hline$(30)$ & $3 \alpha$-Acetoxy- $5 \alpha$-pregnan-20-one & 4.10 & - & - & - & - \\
\hline$(31)$ & $3 \alpha$-Sulfate- $5 \alpha$-pregnan-20-one ${ }^{c}$ & $>10 \mu \mathrm{M}$ & - & - & - & - \\
\hline$(32)$ & $3 \beta$-Hydroxy-5 $\alpha$-pregnan-20-one & 2.25 & -9.54 & 10.1 & 5.26 & 160.9 \\
\hline (33) & $3 \alpha$-Hydroxy-5 $\beta$-pregnan-20-one & 0.24 & -10.09 & 4.03 & 5.70 & 150.6 \\
\hline$(34)$ & $3 \beta$-Hydroxy- $5 \beta$-pregnan-20-one & 1.70 & -10.57 & 1.78 & 5.59 & 146.7 \\
\hline$(35)$ & $3 \alpha, 11 \beta$-Dihydroxy- $5 \alpha$-pregnan-20-one & 1.50 & - & - & - & - \\
\hline$(36)$ & $3 \beta, 16 \alpha$-Dihydroxy- $5 \alpha$-pregnan-20-one & 11.5 & - & - & - & - \\
\hline$(37)$ & 3 $\beta$-Pregnan-3-one & $>10 \mu \mathrm{M}$ & - & - & - & \\
\hline \multicolumn{7}{|c|}{ (D) 4-Androstene steroids } \\
\hline$(38)$ & 4-Androsten-3,17-dione & 10.0 & -11.13 & 0.693 & 5.53 & 156.1 \\
\hline (39) & 4-Androsten-3-one; $17-\beta$-carboxylaic acid & $>10 \mu \mathrm{M}^{\mathrm{e}}$ & - & - & - & - \\
\hline$(40)$ & 4-Androsten-3-one;17- $\beta$-carboxylaic acid methyl ester & 8.01 & - & - & - & - \\
\hline$(41)$ & Testosterone & 14.5 & -10.02 & 4.49 & 4.34 & 151.5 \\
\hline
\end{tabular}


TABle 2: Continued.

\begin{tabular}{|c|c|c|c|c|c|c|}
\hline No. & Trivial name $\left({ }^{\circ}\right)$ & $\begin{array}{l}{\left[{ }^{3} \mathrm{H}\right] \text { PROG } 16 \alpha-} \\
\text { hydroxylation } \\
\left(\mathrm{IC}_{40} \times 10^{-7} \mathrm{M}\right)^{\mathrm{a}}\end{array}$ & $\begin{array}{l}\Delta G_{b} \\
(\mathrm{kcal} / \mathrm{mol})\end{array}$ & $\begin{array}{l}\text { Inhibition } \\
\text { constant } \\
\left(\mathrm{Ki}, \mathrm{\times} 10^{-8}\right)\end{array}$ & $\begin{array}{l}\text { Distance } \\
(\AA)\end{array}$ & $\begin{array}{l}\text { Angle } \\
(0)\end{array}$ \\
\hline \multicolumn{7}{|c|}{ (E) 5-Androstene steroids } \\
\hline$(42)$ & $17 \beta$-Acetoxytestosterone & $>10 \mu \mathrm{M}$ & - & - & - & - \\
\hline (43) & Dehydroepiandrosterone & 6.80 & - & - & - & - \\
\hline$(44)$ & Dehydroepiandrosterone-3-sulfate & $>10 \mu \mathrm{M}$ & -12.91 & 0.0346 & 4.06 & 140.9 \\
\hline$(45)$ & 5-Androstenediol & 6.40 & -10.29 & 2.88 & 4.24 & 160.1 \\
\hline \multicolumn{7}{|c|}{ (F) $5 \alpha$ - or $5 \beta--$ Androstane steroids } \\
\hline$(46)$ & $5 \alpha$-Androstane & $>10 \mu \mathrm{M}$ & -9.69 & 7.94 & 5.90 & 136.4 \\
\hline (47) & $5 \beta$-Androstane & $>10 \mu \mathrm{M}$ & -9.66 & 8.26 & 5.94 & 149.8 \\
\hline$(48)$ & $5 \alpha$-Androstan- $3 \alpha$-ol & 10.3 & -10.00 & 4.67 & 6.0 & 139.5 \\
\hline (49) & $5 \alpha$-Androstan- $3 \beta$-ol & 6.5 & -10.58 & 1.75 & 4.0 & 139.2 \\
\hline (50) & $5 \beta$-Androstan- $3 \alpha$-ol & 5.10 & -9.50 & 10.8 & 4.55 & 145.3 \\
\hline$(51)$ & $5 \beta$-Androstan-3 $\beta$-ol & 1.60 & -9.93 & 5.30 & 4.49 & 165.7 \\
\hline$(52)$ & $5 \alpha$-Androstan- $17 \beta$-ol & $>10 \mu \mathrm{M}$ & - & - & - & - \\
\hline (53) & $5 \beta$-Androstan- $17 \beta$-ol & 3.65 & -10.22 & 3.20 & 5.87 & 150.6 \\
\hline (54) & $5 \alpha$-Androstan-3,17-dione & 6.50 & - & - & - & - \\
\hline$(55)$ & $5 \beta$-Androstan-3,17-dione & 4.80 & -9.98 & 4.80 & 5.67 & 155.2 \\
\hline (56) & $3 \alpha$-Hydroxy- $5 \alpha$-Androstan-17-one & 6.35 & -9.69 & 7.89 & 5.51 & 153.1 \\
\hline$(57)$ & $3 \beta$-Hydroxy- $5 \alpha$-Androstan-17-one & 4.80 & -10.20 & 3.34 & 4.69 & 160.9 \\
\hline (58) & $3 \alpha$-Hydroxy- $5 \beta$-Androstan-17-one & 6.50 & -10.00 & 4.68 & 5.64 & 155.4 \\
\hline (59) & $3 \beta$-Hydroxy- $5 \beta$-Androstan-17-one & 1.85 & -10.28 & 2.92 & 4.12 & 158.0 \\
\hline$(60)$ & $5 \alpha$-Dihydrotestosterone & 11.5 & - & - & - & - \\
\hline (61) & $5 \beta$-Dihydrotestosterone & 6.00 & -10.23 & 3.15 & 5.64 & 151.1 \\
\hline$(62)$ & $5 \alpha$-Androstan- $3 \alpha, 17 \beta$-diol & 1.25 & - & - & - & - \\
\hline (63) & $5 \alpha$-Androstan- $3 \alpha, 17 \beta$-diol-17-acetate & 3.00 & - & - & - & - \\
\hline (64) & $5 \alpha$-Androstan- $3 \alpha, 17 \beta$-diol-17-sulfate ${ }^{c}$ & $>10 \mu \mathrm{M}$ & -10.37 & 2.51 & 5.45 & 145.8 \\
\hline$(65)$ & $5 \alpha$-Androstan- $3 \beta, 17 \beta$-diol & 11.1 & - & - & - & - \\
\hline$(66)$ & $5 \beta$-Androstan-3 $\alpha, 17 \beta$-diol & 0.69 & -10.29 & 2.86 & 5.82 & 150.0 \\
\hline$(67)$ & $5 \beta$-Androstan- $3 \alpha$-ol-17 $\beta$-carboxylic acid & 3.60 & -11.87 & 0.201 & 5.0 & 138.3 \\
\hline (68) & $5 \beta$-Androstan- $3 \alpha$-ol- $1 \beta$-carboxylic acid methyl ester & 0.43 & -10.81 & 1.20 & 5.47 & 156.0 \\
\hline$(69)$ & $5 \beta$-Androstan-3 $\beta, 17 \beta$-diol & 3.20 & -10.69 & 1.46 & 4.14 & 148.8 \\
\hline \multicolumn{7}{|c|}{ (G) Estogens } \\
\hline (70) & Estradiol- $17 \beta$ & $>10 \mu \mathrm{M}$ & - & - & - & - \\
\hline$(71)$ & Estradiol-17 $\alpha$ & $>10 \mu \mathrm{M}$ & -9.75 & 7.11 & 4.15 & 135.1 \\
\hline
\end{tabular}

${ }^{\mathrm{a}} \mathrm{IC}_{40}$ value was defined as the molar concentration $\left(\times 10^{-7} \mathrm{M}\right)$ of an unlabeled steroid causing $40 \%$ inhibition of [ $\left.{ }^{3} \mathrm{H}\right] \mathrm{PROG} 16 \alpha$-hydroxylation.

${ }^{\mathrm{b}}$ Docking results are not matched with the required parameters (distance $=4-6 \AA$ and angle $=180 \pm 45^{\circ}$ ).

${ }^{c,}{ }^{\mathrm{e}}$ These imply the mean values of $\%$ inhibition ${ }^{c, d}{ }^{\mathrm{I}} \mathrm{C}_{40}$ value $\left(\times 10^{-7} \mathrm{M}\right)$ obtained from extrapolation, and $\%$ increase ${ }^{\mathrm{e}}$, respectively, at $10 \mu \mathrm{M}$ of the relevant unlabeled compound.

whether the correlation coefficient is positive or not. In order to examine this relationship, the correlation between the AutoDock inhibition constant (Ki) of steroid substrates and the inhibition potency $\left(\mathrm{IC}_{40}\right)$ against $\left[{ }^{3} \mathrm{H}\right]$ progesterone $16 \alpha$ hydroxylation of the rat liver microsome was plotted. As shown is Figure 5, the correlation coefficient was positive and it showed that our model and described enzymatic mechanism were valid.

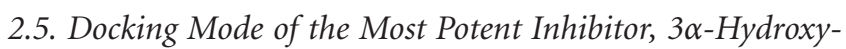
5 $\beta$-Pregnan-20-One (33). The steroid molecule $3 \alpha$-hydroxy-
$5 \beta$-pregnan-20-one (33), as shown in Table 2, exhibited the highest number of the conformations met with the abovementioned conditions with the lowest binding free energy $(\Delta \mathrm{Gb})$ of $-10.09 \mathrm{kcal} / \mathrm{mol}$, and the minimum inhibition constant $(\mathrm{Ki})$ of $4.03 \times 10^{-8}$, that is, with the highest binding affinity $\left(\mathrm{IC}_{40} ;=0.24 \times 10^{-7} \mathrm{M}\right)$ within the CYP2C11 binding site pocket. The docked inhibitor 33 , as shown in Figure 4, was located within $5.7 \AA$ between the C16-carbon atom, where the proposed $16 \alpha$-hydroxylation takes place, and the heme iron, and the angle between C16-carbon, C16- $\alpha$-hydrogen, and the heme iron was $150.6^{\circ}$. The RMSD 
(distance in $\AA$, measured between the centeroid of the docked substrate and that of the bound ligand, flurbiprofen) was $1.03 \AA$. Also, the inhibitor 33 showed a bent A-B ring configuration within the binding site pocket, as shown in Figure 3(b).

2.6. Docking Modes of the Other Pertinent Steroid Molecules: $1,29,32,34,38$, and 56. Docking of other inhibitors, namely $1,29,32,34,38$, and 56 , met the condition requirement exhibiting the favorable distance and angle of their sites of oxidation and the heme iron. They are positioned so that their C16-carbon atoms be located within 5.73, 5.82, 5.26, $5.59,5.53$, and $5.51 \AA$ from the heme iron, respectively, and their angles between C16-carbon, C16- $\alpha$-hydrogen, and the heme iron were $144.8^{\circ}, 148.9^{\circ}, 160.9^{\circ}, 146.7^{\circ}, 156.1^{\circ}$, and $153.1^{\circ}$, respectively. Their corresponding RMSD were 0.92 , $1.07,0.73,0.71,0.82$, and $4.65 \AA$, respectively. Thus, it was noticed that these substrates were docked exactly in the same position within the binding site pocket and they seem to superimpose with the bound ligand, flurbiprofen, as their RMSD distances are quite small with the average of $1.48 \AA$. Out of the above six inhibitors, Figures 3 and 4 illustrate the actual docking mode of inhibitors $32,33,34,38$, and 56 .

Inhibitors 1 and 38 with 4 -ene A-B ring and inhibitors 29 , and 56 with $5 \alpha$-reduced A-B ring are shown in Figure 3 with planar A-B ring configuration, whereas inhibitor 34 with $5 \beta$-reduced $\mathrm{A}-\mathrm{B}$ ring exhibited bent $\mathrm{A}-\mathrm{B}$ ring configuration within the binding site.

\section{Conclusion}

Computer simulated automated docking studies were performed using AutoDock 3.05. Docking results revealed that there was a variety of conformations of the docked inhibitors meeting the confirmation of the reported orientation requirements of steroids within their binding sites $[7$, $13,21]$. The docked inhibitors were shown to be positioned so that the site of hydroxylation (C16-carbon) resides within 5-6 $\AA$ from the heme iron, which is consistent with the distances seen in the case of other P450 substrate complex, with the angle between C16-carbon, C16 $\alpha$ - hydrogen, and the heme iron being $180 \pm 45.0^{\circ}$. It was noticed that steroids were docked exactly overlapped with the flurbiprofen, as their average RMSD was $1.98 \AA$. Also a positive correlation was obtained between the observed inhibitory potencies against $\left[{ }^{3} \mathrm{H}\right]$ PROG $16 \alpha$-hydroxylation and the binding free energies of the docked steroids. The correlation between the observed inhibitory potencies and AutoDock inhibition constants (ki), exhibited also a positive correlation coefficient. Steroid molecule 33 exhibited the lowest binding free energy, that is, the highest affinity within the binding site of CYP2C11, and with the highest number of conformations meeting the reported requirements. This agrees well with the biologically observed results; its observed inhibitory potency index against $\left[{ }^{3} \mathrm{H}\right] \mathrm{PROG} 16 \alpha$-hydroxylation was 31.46 ( $\mathrm{IC}_{40} ;: 3 \alpha$-hydroxy-5 $\beta$-pregnan-20-one $33,0.24 \times$ $10^{-7} \mathrm{M}$, vs. progesterone $1,7.55 \times 10^{-7} \mathrm{M}$ ).

As a whole, the results of the present docking investigation revealed that many amino acid residues responsible for binding of the flurbiprofen-bound CYP2C9 (1r9o), were also essential for the interaction between CYP2C11 and inhibitors. Moreover, docking of steroid molecules within the 3-D homology model of CYP2C11 based on that of warfarinbound CYP2C9 $(\log 5)$, CYP2C9 $(\log 2)$, and flurbiprofenbound CYP2C9 $(\log 5)$, were in a fair agreement with the observed biological data.

\section{Methods}

\subsection{Experimental Procedures}

4.1.1. Materials. [1,2-3H]Progesterone (PROG) (specific activity, $\quad 49.2 \mathrm{Ci} / \mathrm{mmol})$ and $[9,11,12-3 \mathrm{H}] 3 \alpha-\mathrm{OH}-5 \alpha-$ $\mathrm{P}$ (specific activity, $65.0 \mathrm{Ci} / \mathrm{mmol}$ ) were obtained from PerkinElmer life Sciences, U.S.A. and purified by paper chromatographic system of hexane and saturated formamide $(\mathrm{H} / \mathrm{F})$. Unlabeled steroids were purchased from Sigma Chemical Company, St. Louis, Mo, U.S.A., and Steraloids, Inc., Wilton, N.H., U.S.A. Whatman No.1 filter papers used for paper chromatographies were obtained from Whatman Ltd., England. Other reagents were of analytical grade.

4.2. Preparation of Adult Male Rat Liver Microsomes. Approximately 95-day-old male Wistar rats, castrated on the 70th day after birth, were used. The liver microsomes were prepared as previously described $[29,31]$. The experiments were performed according to instrumental guidelines for the care and use of laboratory animals.

4.3. [3H]PROG Metabolism by Rat Liver MicrosomesInhibitory Effects of Various Unlabeled Steroids. The metabolism by rat liver microsomes were examined, according to our previously described procedure [23-25]. Briefly, the microsomal suspension $(400-600 \mu \mathrm{g}$ of protein $/ 2.2 \mathrm{~mL}$, total volume of the reaction mixture) was preincubated with [3H]PROG $(20 \mathrm{nM})$ under the absence or presence of an unlabeled steroid $(0.01-10 \mu \mathrm{M})$ at $36^{\circ} \mathrm{C}$ for $30 \mathrm{~min}$. Then NADH $(3.16 \mu \mathrm{M})$ was added, and the reaction mixture was incubated further for 5 min. After the incubation, two identical samples were mixed and extracted with toluene. The toluene-extractable [3H]PROG metabolites (more than 90\%) were isolated by various paper chromatographic systems and then identified by recrysallization method [26]. Other miscellaneous procedures are described in our previous papers [29,31].

4.4. Protein Homology Modeling. Since the crystal structure of CYP2C11 is not available, the three dimensional (3D) model of CYP2C11 used in the present simulation was constructed based on a homology modeling method. The homology modeling procedure and the sequence alignment were performed with the cooperation of Swiss-Model (Swiss-Model version 36.0003) [17, 18]. Comparative modeling techniques were used to prepare homology model of CYP 2C11. Several homologous crystal structures were referred to as template structures. The amino acid sequence for the desired protein was referred to as the target. The crystal template structures were selected from 


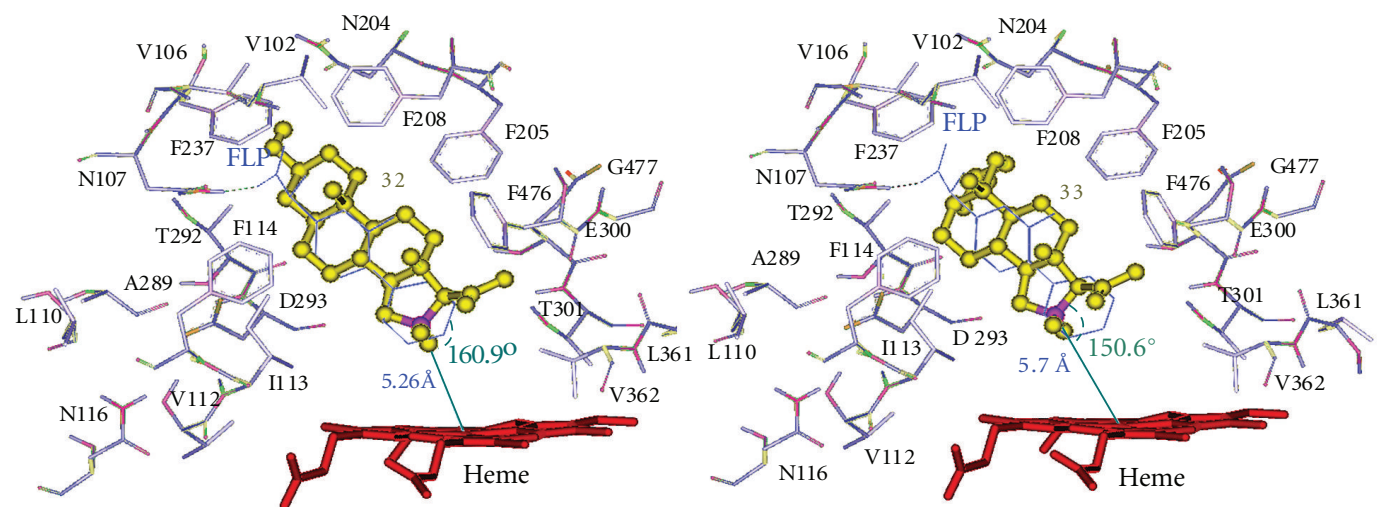

(a)
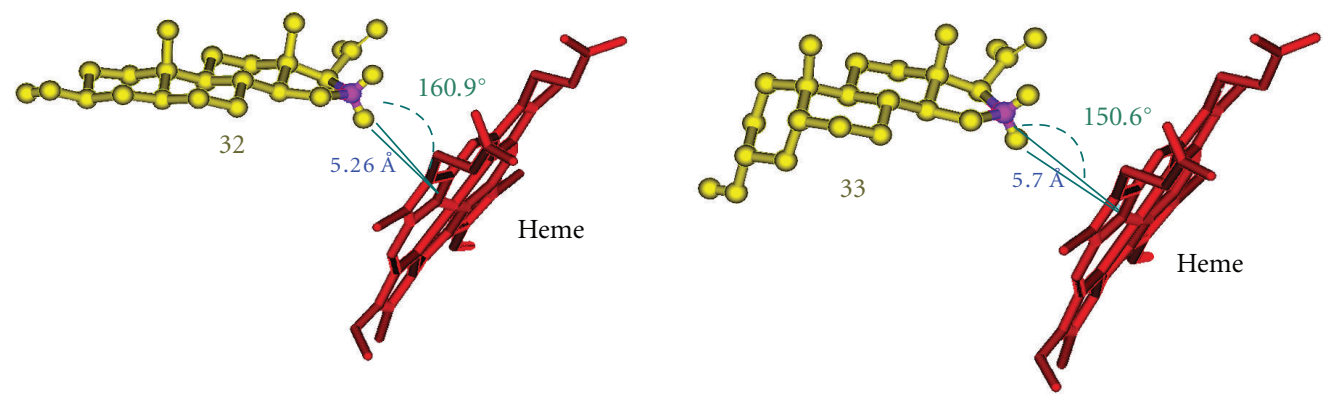

(b)

FIGURE 3: Docking configurations of inhibitors 32 and 33 (yellow ball and stick) into the homology-modeled CYP2C11 where amino acid residues G296, A297, and L366 are hidden for clarity. (a) The relevant amino acid (wire, colored by atoms) biding sites with the inhibitors are shown, and both inhibitors are docked in a superimposed fashion with the embedded substrate flurbiprofen (FLP, wire in blue) within RMSD of 0.93 and $0.79 \AA$, respectively. (b) Inhibitor 32 exhibits the planar A-B ring binding configuration with heme molecule (stick in red), while inhibitor 33, the bent A-B ring binding configuration. The distance between C16-carbon of inhibitor 32 and the heme iron is $5.26 \AA$ with the angle between C16 carbon, C16- $\alpha$ hydrogen, and the heme iron being $160.9^{\circ}$, while the formaer of inhibitor $33,5.70 \AA$, and the latter, $150.6^{\circ}$.

ExPDB template database to identify suitable template structures for the comparative modeling. The following templates of 500 sequences residues were downloaded from Brookhaven PDB (http://rcsb.org/pdb/): CYP2C9 with warfarin bound, PDB code, log5; CYP2C9, PDB code, log2; CYP2C9 complexed with flurbiprofen bound, PDB code, 1r9o; CYP2C8, PDB code, 1pq2; CYP2C5/3LVdH complexed with a bound substrate, 4-methyl-N-methyl-N-(2-phenyl2H-pyrazol-3-yl)benzenesulfonamide (DMZ), PDB code, 1n6b; CYP2C5/3LVdH complexed with diclofenac, PDB code, 1nr6; CYP2C5, PDB code, 1dt6; CYP2B4 with 4-(4Chlorophenyl) imidazole bound, PDB code, 1suo; CYP2B4, PDB code, 1po5; CYP2A6 with methoxsalen bound, PDB code, lzll; CYP2A6 with coumarin bound, PDB code, 1zl0; CYP3A4, PDB code, 1tqn; CYP3A4 with progesterone bound, PDB code, 1w0f; CYP3A4 with metyrapone bound, PDB code, 1w0g; CYP3A4, PDB code, 1w0e; CYP51 with estriol bound, PDB code, 1x8v; CYP51 in ferric low spin state, PDB code, 1h5z; C37L/C151T/C442A-triplet mutant of CYP51, PDB code, 1ul3; CYP51 with 4-phenylimidazole bound, PDB code, 1e9x; CYP51 with fluconazole bound, PDB code, 1ea1. The target sequence was downloaded from the SWISS-PROT database (http://us.expasy.org/sprot/) (accession number P08683). Running pairwise alignments of the target sequence with that of the template were carried out and the sequence identity of templates with the target is shown in Table 1. Those templates of 1x8vA.pdb, 1h5zA.pdb, lu13A.pdb, 1e9xA.pdb, and 1ea1A.pdb, whose percentages of identity were $23.3 \%, 23.9 \%, 23.9 \%, 23.9 \%$, and $23.9 \%$, respectively, had been rejected due to their too low similarities with the target sequence. The sequence alignment was followed by adding the missing side chains, adding hydrogens, and optimizing loops and OXT $(\mathrm{nb}=1)$; and the final total energy was- $17460.258 \mathrm{KJ} / \mathrm{mol}$, and then hydrogens were finally removed.

4.5. Automated Docking. Computer-simulated automated docking studies were performed using the widely distributed molecular docking software, AutoDock 3.05, a grid-based docking program [33], which was utilized for the study of binding mode of inhibitors within CYP2C11. This program addresses automatically the flexible docking of the ligands into a known protein structure. In contract, flexibility of the target protein is not taken into account.

AutoDock 3.05 scans the active site for low energy binding models and for suitable orientations of the probe 


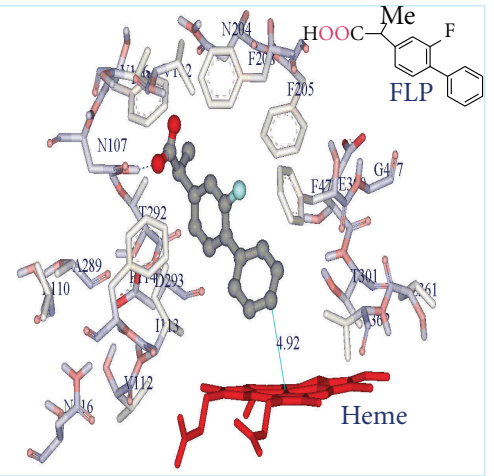

(a)

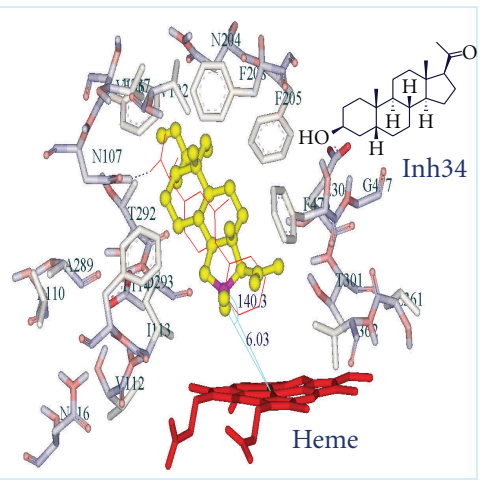

(d)

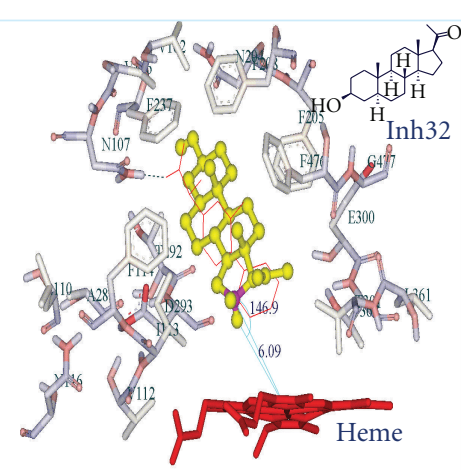

(b)

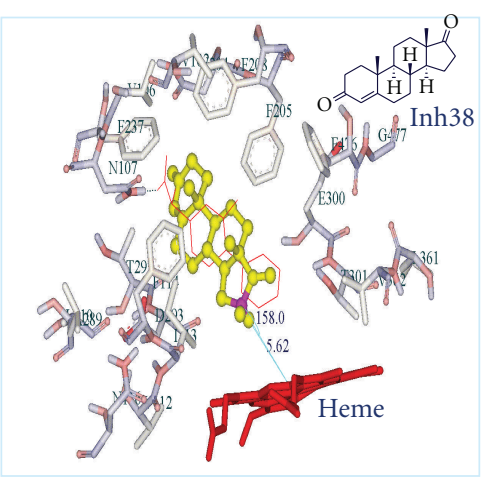

(e)

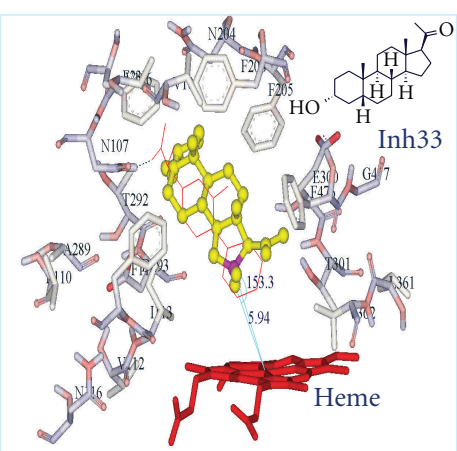

(c)

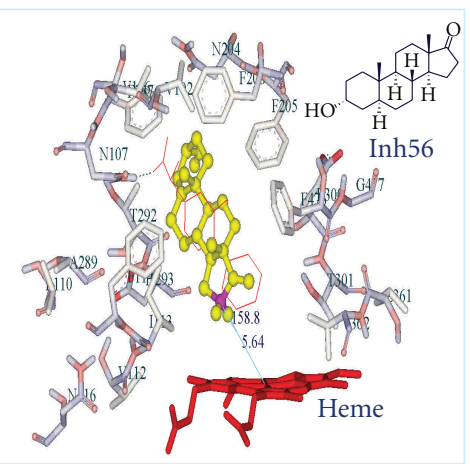

(f)

FIGURE 4: The docking modes of different inhibitors, inh32, inh33, inh34, and inh56 (inhibitor code), are shown with ball and stick in yellow within the binding site pocket of Cyt P450-2C11. The embedded ligand, flurbiprofen (FLP, ball and stick colored by atoms) is bound inside the pocket of the homology-modeled Cyt P450-2C11. All inhibitors are docked within the distance of 4-6 $\AA$ (shown in lines and 3 digit numbers) between $\mathrm{C} 16$ and the iron atom of heme molecule (shown as red, stick) and with the angel between the 16C $\alpha$-hydrogen and the iron of heme molecule being $180+45^{\circ}$ (shown in lines and 4 digit numbers). Pertinent amino acids (ASN107, ILE113, PHE114, ASN204 PHE205, PHE237 THR292, ASP293, GLY296, ALA297, GLU300, THR301, and LEU366) lay within $4 \AA$ of all docked steroid molecules and are shown in stick, colored by atoms. Hydrogen bond formation is shown in dotted line between the inhibitor and amino the acid residue.

molecule, using a modified genetic algorism that employs a local search (GALS) and precomputed grids for the evaluation of the interaction energy. The target homologymodeled protein CYP2C11 was separated alone by using DS modeling 1.1 software (DS modeling 1.1; Accelrys inc., San Diego, CA (2003)) and representative amino acids of the ligand-binding site were selected within $5 \AA$ neighborhood surrounding the embedded ligand, flurbiprofen. A $120 \AA$ $120 \AA 120 \AA$ grid size $(\mathrm{x}, \mathrm{y}, \mathrm{z})$ with a spacing of $0.300 \AA$ centered at $-18.44,86.67$, and $30.89 \AA$ that encompassed the active site where the ligand, flurbiprofen, was embedded, was used to guide the docked inhibitors. The results of 250 randomly seeded runs were analyzed for each of the docked inhibitors. The docked inhibitors were assigned to a cluster if the atomic coordinates of the docked inhibitors exhibited a root-mean-square deviation (RMSD) of less than $0.5 \AA$ difference from each other (RMSD-tolerance of $0.5 \AA$ ). The clusters were ranked from the averaged lowest energy obtained for members of the cluster to the highest. The analysis was carried out for the top 10 docking clusters. Each of the clusters that exhibited significant negative interaction energies was examined by DS modeling program to determine their binding orientations.

4.6. Preparation of Small Molecules. ChemDraw ultra 8.0 software (Chemical Structure Drawing Standard; Cambridge Soft Corporation, USA(2003)) was used for construction of compounds which were converted to $3 \mathrm{D}$ structures using Chem 3D ultra 8.0 software (Molecular Modeling and Analysis; Cambridge Soft Corporation, USA(2003)) and the constructed $3 \mathrm{D}$ structures were energetically minimized by using MOPAC with 100 iterations and minimum RMS gradient of 0.10 .

4.7. Evaluation of Docked Results. DS modeling 1.7 was utilized for the molecular modeling and the evaluation of $\mathrm{H}$-bonds in ligand-receptor interaction and for the measurement of RMSD, which was computed and expressed in angstrom $(\AA)$ as a locational comparison of two relevant molecules of interest. In the actual sense, it was measured as a distance between the centroid of the docked inhibitor and the bound-ligand, flurbiprofen (FLP). 


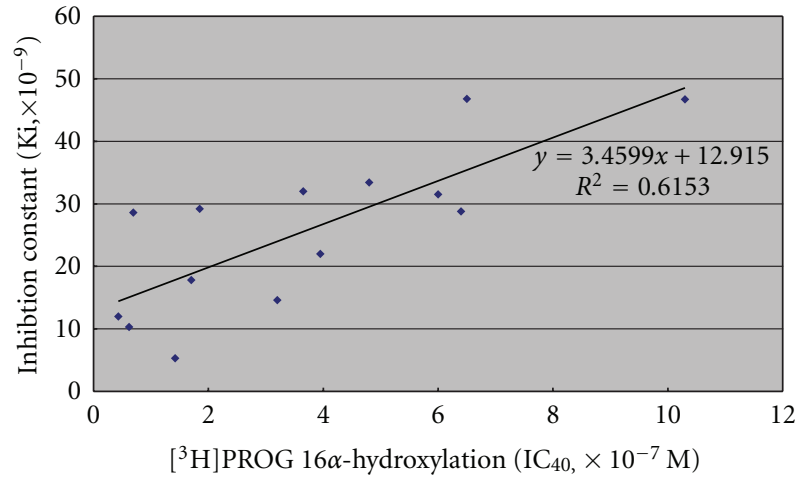

Figure 5: Correlation relationship between the AutoDock inhibition constant (Ki) of tested steroid substrates and inhibition potencies $\left(\mathrm{IC}_{50}\right.$ ) against $\left[{ }^{3} \mathrm{H}\right]$ PROG $16 \alpha$-hydroxylation by rat liver microsomes- three outsider points were eliminated.

\section{Competing Interest}

The authors declare that they have no competing financial interest.

\section{Acknowledgments}

The current work was supported in part by Grants-in-Aid for Scientific Research of the Japan Society for the Promotion of Science in Japan. It was also supported by Collaborative Research Grant A of Kobe Gakuin University in Japan. The authors are grateful to each organization for their generous support for our current work. The authors are grateful to the technical works carried out by Ms. Hitomi Kawatsura and Mr. Michihiko Tanaka, former students of Kobe Gakuin University.

\section{References}

[1] Z. K. Ali, R. J. Kim, and F. M. Ysla, "CYP2C9 polymorphisms: considerations in NSAID therapy," Current Opinion in Drug Discovery and Development, vol. 12, no. 1, pp. 108-114, 2009.

[2] J. B. Hagan, R. L. Taylor, R. J. Singh, J. C. Seegmiller, B. C. Netzel, and N. L. Korpi-Steiner, Fluticasone Propionate and Its Metabolite in Urine of Human for Treatment Compliance Assessment, Mayo Foundation for Medical Education and Research, 2009.

[3] Y. S. Kang, S. Y. Park, C. H. Yim et al., "The CYP3A4* 18 genotype in the cytochrome $\mathrm{P} 450$ 3A4 gene, a rapid metabolizer of sex steroids, is associated with low bone mineral density," Clinical Pharmacology and Therapeutics, vol. 85, no. 3, pp. 312-318, 2009.

[4] V. Luu-The, D. Duche, C. Ferraris, J.-R. Meunier, J. Leclaire, and F. Labrie, "Expression profiles of phases 1 and 2 metabolizing enzymes in human skin and the reconstructed skin models Episkin ${ }^{\mathrm{TM}}$ and full thickness model from Episkin ${ }^{\mathrm{TM}}$," Journal of Steroid Biochemistry and Molecular Biology, vol. 116, no. 3-5, pp. 178-186, 2009.

[5] A. Mahmood, A. Kachurin, W. Warren, and R. Higbee, Artificial Tissue Constructs Comprising Alveolar Cells Epithelial and Endothelial Layers and Methods for Using the Same as in
Vitro Models of Mammalian Lung Tissue for Study of Lung Diseases, Vaxdesign, Minneapolis, Minn, USA, 2009.

[6] L. M. Scott, P. Durant, S. Leone-Kabler et al., "Effects of prior oral contraceptive use and soy isoflavonoids on estrogenmetabolizing cytochrome P450 enzymes," Journal of Steroid Biochemistry and Molecular Biology, vol. 112, no. 4-5, pp. 179185, 2008.

[7] Y.-Y. Zhang and L. Yang, "Interactions between human cytochrome P450 enzymes and steroids: physiological and pharmacological implications," Expert Opinion on Drug Metabolism and Toxicology, vol. 5, no. 6, pp. 621-629, 2009.

[8] G. D. Szklarz, R. L. Ornstein, and J. R. Halpert, "Application of 3-dimensional homology modeling of cytochrome P450 2B1 for interpretation of site-directed mutagenesis results," Journal of Biomolecular Structure and Dynamics, vol. 12, no. 1, pp. 6178, 1994.

[9] G. A. Dannan, F. P. Guengerich, and D. J. Waxman, "Hormonal regulation of rat liver microsomal enzymes. Role of gonadal steroids in programming, maintenance, and suppression of $\Delta 4$-steroid $5 \alpha$-reductase, flavin-containing monooxygenase, and sex-specific cytochromes P-450," Journal of Biological Chemistry, vol. 261, no. 23, pp. 10728-10735, 1986.

[10] S. Imaoka, S. Fujita, and Y. Funae, "Age-dependent expression of cytochrome P-450s in rat liver," Biochimica et Biophysica Acta, vol. 1097, no. 3, pp. 187-192, 1991.

[11] J. B. Schenkman, "Steroid metabolism by constitutive cytochromes P450," Journal of Steroid Biochemistry and Molecular Biology, vol. 43, no. 8, pp. 1023-1030, 1992.

[12] W. Li, H. Liu, E. E. Scott et al., "Possible pathway(s) of testosterone egress from the active site of cytochrome P450 2B1: a steered molecular dynamics simulation," Drug Metabolism and Disposition, vol. 33, no. 7, pp. 910-919, 2005.

[13] G. D. Szklarz and J. R. Halpert, "Use of homology modeling in conjunction with site-directed mutagenesis for analysis of structure-function relationships of mammalian cytochromes P450," Life Sciences, vol. 61, no. 26, pp. 2507-2520, 1997.

[14] S. Kumar, E. E. Scott, H. Liu, and J. R. Halpert, "A rational approach to re-engineer cytochrome $\mathrm{P} 4502 \mathrm{~B} 1$ regioselectivity based on the crystal structure of cytochrome P450 2C5," Journal of Biological Chemistry, vol. 278, no. 19, pp. 1717817184, 2003.

[15] M. R. Wester, E. F. Johnson, C. Marques-Soares, P. M. Dansette, D. Mansuy, and C. D. Stout, "Structure of a substrate complex of mammalian cytochrome P450 2C5 at $2.3 \AA$ resolution: evidence for multiple substrate binding modes," Biochemistry, vol. 42, no. 21, pp. 6370-6379, 2003.

[16] M. R. Wester, E. F. Johnson, C. Marques-Soares et al., "Structure of mammalian cytochrome P450 2C5 complexed with diclofenac at $2.1 \AA$ resolution: evidence for an induced fit model of substrate binding," Biochemistry, vol. 42, no. 31, pp. 9335-9345, 2003.

[17] P. A. Williams, J. Cosme, V. Sridhar, E. F. Johnson, and D. E. McRee, "Mammalian microsomal cytochrome P450 monooxygenase: structural adaptations for membrane binding and functional diversity," Molecular Cell, vol. 5, no. 1, pp. 121-131, 2000.

[18] T. Schwede, J. Kopp, N. Guex, and M. C. Peitsch, "SWISSMODEL: an automated protein homology-modeling server," Nucleic Acids Research, vol. 31, no. 13, pp. 3381-3385, 2003.

[19] N. Guex and M. C. Peitsch, "SWISS-MODEL and the SwissPdbViewer: an environment for comparative protein modeling," Electrophoresis, vol. 18, no. 15, pp. 2714-2723, 1997. 
[20] P. A. Williams, J. Cosme, A. Ward, H. C. Angove, D. M. Vinković, and H. Jhoti, "Crystal structure of human cytochrome P450 2C9 with bound warfarin," Nature, vol. 424, no. 6947, pp. 464-468, 2003.

[21] M. R. Wester, J. K. Yano, G. A. Schoch et al., "The structure of human cytochrome P450 2C9 complexed with flurbiprofen at 2.0-Å resolution," Journal of Biological Chemistry, vol. 279, no. 34, pp. 35630-35637, 2004.

[22] G. A. Schoch, J. K. Yano, M. R. Wester, K. J. Griffin, C. D. Stout, and E. F. Johnson, "Structure of human microsomal cytochrome P450 2C8: evidence for a peripheral fatty acid binding site," Journal of Biological Chemistry, vol. 279, no. 10, pp. 9497-9503, 2004.

[23] E. E. Scott, Y. A. He, M. R. Wester et al., "An open conformation of mammalian cytochrome P450 2B4 at 1.6- $\AA$ resolution," Proceedings of the National Academy of Sciences of the United States of America, vol. 100, no. 23, pp. 13196-13201, 2003.

[24] J. K. Yano, M.-H. Hsu, K. J. Griffin, C. D. Stout, and E. F. Johnson, "Structures of human microsomal cytochrome P450 2A6 complexed with coumarin and methoxsalen," Nature Structural and Molecular Biology, vol. 12, no. 9, pp. 822-823, 2005.

[25] J. K. Yano, M. R. Wester, G. A. Schoch, K. J. Griffin, C. D. Stout, and E. F. Johnson, "The structure of human microsomal cytochrome P450 3A4 determined by X-ray crystallography to 2.05-Å resolution," Journal of Biological Chemistry, vol. 279, no. 37, pp. 38091-38094, 2004.

[26] P. A. Williams, J. Cosme, D. Matak Vinković et al., "Crystal structures of human cytochrome P450 3A4 bound to metyrapone and progesterone," Science, vol. 305, no. 5684, pp. 683-686, 2004.

[27] L. M. Podust, L. V. Yermalitskaya, G. I. Lepesheva, V. N. Podust, E. A. Dalmasso, and M. R. Waterman, "Estriol bound and ligand-free structures of sterol $14 \alpha$-demethylase," Structure, vol. 12, no. 11, pp. 1937-1945, 2004.

[28] L. M. Podust, T. L. Poulos, and M. R. Waterman, "Crystal structure of cytochrome P450 14 $\alpha$-sterol demethylase (CYP51) from Mycobacterium tuberculosis in complex with azole inhibitors," Proceedings of the National Academy of Sciences of the United States of America, vol. 98, no. 6, pp. 30683073, 2001.

[29] M. D. Paulsen and R. L. Ornstein, "Predicting the product specificity and coupling of cytochrome P450cam," Journal of Computer-Aided Molecular Design, vol. 6, no. 5, pp. 449-460, 1992.

[30] M. Yamada, K. Indo, T. Nishigami, K. Nakasho, and H. Miyaji, "Progesterone-binding site of adult male rat liver microsomes," Journal of Biological Chemistry, vol. 265, no. 19, pp. 11035-11043, 1990.

[31] M. Yamada, T. Nishigami, K. Nakasho, Y. Nishimoto, and H. Miyaji, "Relationship between sigma-like site and progesterone-binding site of adult male rat liver microsomes," Hepatology, vol. 20, no. 5, pp. 1271-1280, 1994.

[32] A. Yamada, M. Yamada, Y. Fujita, T. Nishigami, K. Nakasho, and K. Uematsu, "Self-augmentation effect of male-specific products on sexually differentiated progesterone metabolism in adult male rat liver microsomes," Journal of Biological Chemistry, vol. 276, no. 7, pp. 4604-4610, 2001.

[33] M. Yamada and K. Matsumoto, "Pathway from progesterone to $5 \alpha$ reduced $\mathrm{C} 19$ steroids not involving androstenedione and testosterone in immature rat testes in vitro," Endocrinology, vol. 94, no. 3, pp. 777-784, 1974.
[34] F. De Rienzo, F. Fanelli, M. C. Menziani, and P. G. De Benedetti, "Theoretical investigation of substrate specificity for cytochromes P450 IA2, P450 IID6 and P450 IIIA4," Journal of Computer-Aided Molecular Design, vol. 14, no. 1, pp. 93-116, 2000.

[35] G. M. Morris, D. S. Goodsell, R. S. Halliday et al., "Automated docking using a Lamarckian genetic algorithm and an empirical binding free energy function," Journal of Computational Chemistry, vol. 19, no. 14, pp. 1639-1662, 1998. 


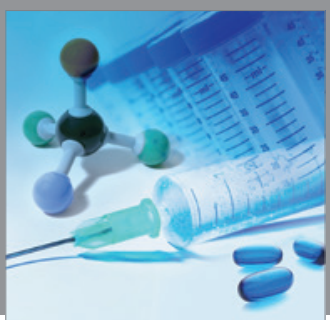

International Journal of

Medicinal Chemistry

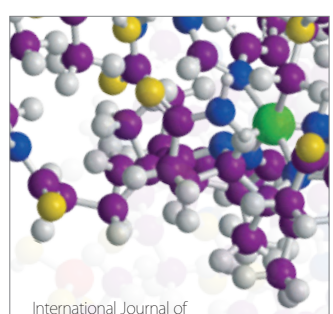

Carbohydrate Chemistry

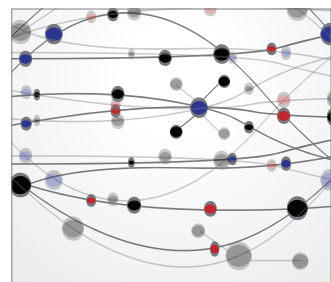

The Scientific World Journal
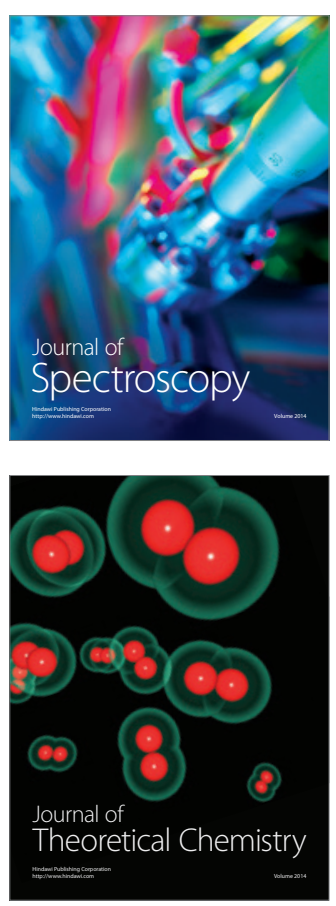
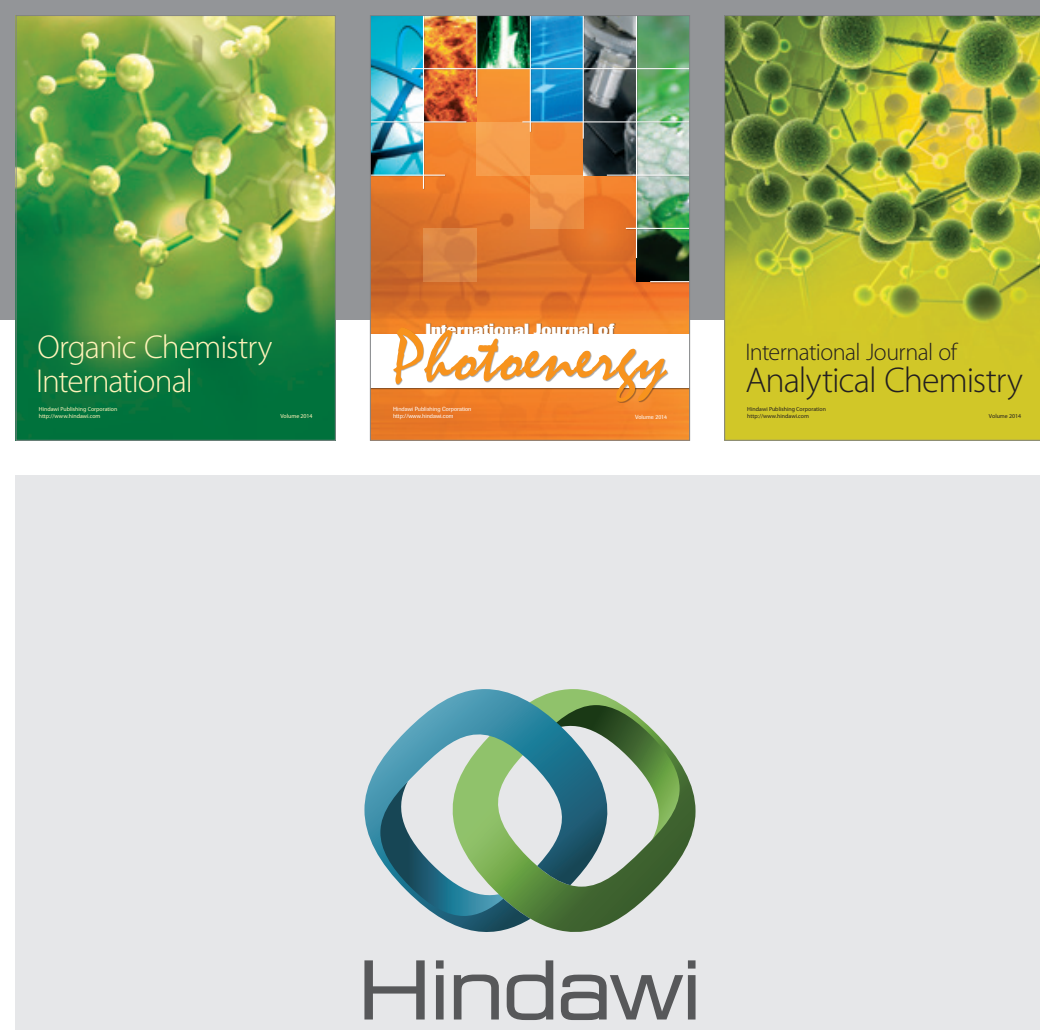

Submit your manuscripts at

http://www.hindawi.com
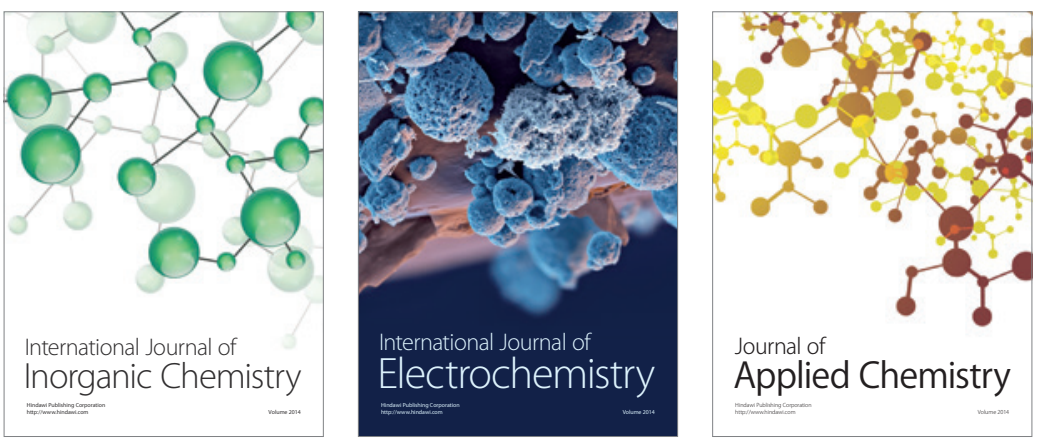

Journal of

Applied Chemistry
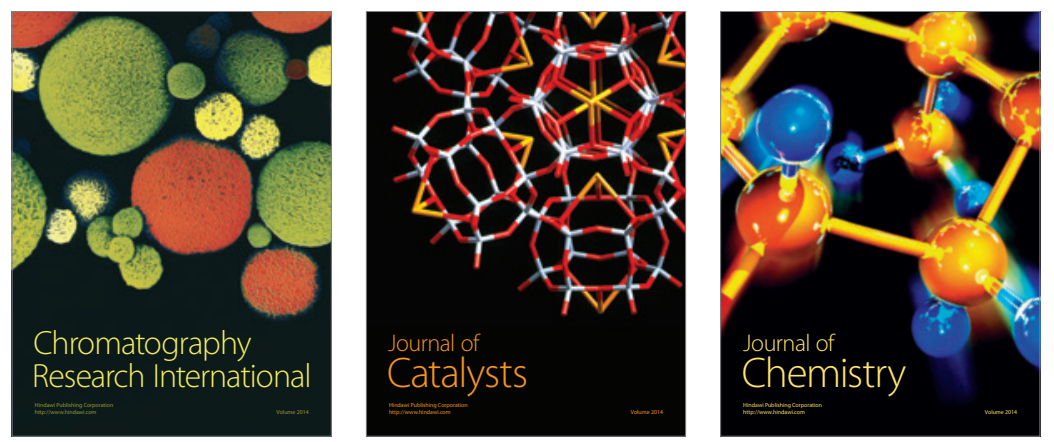
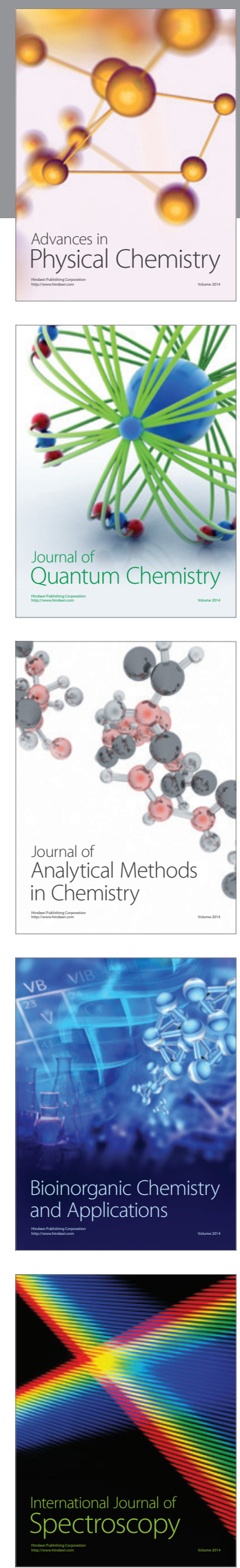